\title{
Motor drive design using structured query language
}

\author{
Valery Vodovozov and Juhan Laugis \\ Department of Electrical Drives and Power Electronics, Tallinn University of Technology, \\ Ehitajate tee 5, 19086 Tallinn, Estonia; laugis@cc.ttu.ee
}

Received 7 April 2008, in revised form 26 September 2008

\begin{abstract}
An integrated design task includes equipment selection, structural synthesis, experiment planning and results processing, as well as improvements in the designed systems. The problem of motor drive design concerns multi-criteria non-linear problems that have a number of solutions. In daily practice, the search for an optimum solution relies mostly on the designer's intuition and experience. Therefore the obtained results have often a low degree of equipment use, unwarranted complexity, or excessive cost. The approach proposed in this paper is based on the implementation of the structured query language into the design stages that improve the work with databases of the drive components. Examples of effective algorithms are given to choose an optimum ratio of electrical and mechanical components. A soft tool is developed to generate and edit query sentences, to extract information from the databases and to test different component sets for particular applications.
\end{abstract}

Key words: motor drive, design, database, structured query language, simulation, modelling, multi-criteria problem.

\section{INTRODUCTION}

An electric drive belongs to the inhomogeneous, non-linear and nonstationary class of systems $\left[{ }^{1}\right]$. The object heterogeneity is reflected by the variety of structural components, informational and energetic processes. Heterogeneity implies a discrete nature of inputs and variables. Power pulse conversion with a continuous electromechanical transformation and continuous-discrete information are also characteristic for these processes. In terms of the reaction to different inputs, electromechanical systems are non-linear. Non-linearity results from the limited code lengths of the controllers and sensors and from non-linear technical chains and program blocks. Other reasons of non-linearity are amplitude modularity of digital-to-analogue conversion, complex signal levels, semi-controllability of power converters, saturation in the magnetic chains of electric machines, plugs and gaps, backslashes, and Coulomb and fluid friction of 
mechanical gears and actuators. The non-stationary property of a motor drive is the result of changes in the system parameters and varying torques and moments of inertia. This feature is taken into account in the description of object behaviour as time-dependent statements.

Therefore the design procedure of a motor drive involves a number of complex problems $\left[{ }^{2}\right]$, such as

- timing calculation and construction of the mechanism travel diagram;

- computation of mechanism forces and torque/power pattern synthesis;

- gear dimensioning and selection;

- motor dimensioning and selection;

- optimum motor-gear set selection and checking;

- power electronic converter dimensioning and selection or design;

- drawing motor drive wiring diagrams;

- design of controllers for multi-loop control and adjustment;

- process simulation along with a steady-state diagram and transient building;

- economic basis and evaluation of efficiency.

The above problems are encountered by designing effective drive systems owing to rather complicated algorithms $\left[^{3}\right]$. In the design community, several techniques of drive design are used today.

First, a manufacturer is selected and then the design technology and recommendations of the manufacturer are provided. To compute and select equipment, leading companies have developed their specific technologies. Examples are the guidelines and software of Siemens $\left[{ }^{4}\right]$, Omron, Sew Eurodrive $\left.{ }^{5}\right]$, Maxon Motors, Mitsubishi Electric etc. The majority of companies uses such approach. They have gained wide experience using extensive computer databases, numerous catalogue archives and "absorbing" their contents and structures. The main drawbacks here are technological restrictions and limited data that deprive a designer of an optimum approach. It is of particular importance in the first stage, when critical decisions are taken.

In the second technique, described in $\left[{ }^{6,7}\right]$, the designers move from the load computation, based on their own experience and methods, to a group of gear families and types of different companies using the load calculation results. Through these gears, the forces and the speed of a mechanism, found before, will be converted to the equivalent values on the motor shaft. Then the motor type is chosen for each gear type, based on the converted forces and speeds. Thus a set of possible drive variants is generated. Once the framework of the equipment is found, a new problem appears - which of the suitable motor-gear combinations is optimum? To find a solution, the designer can formulate appropriate criteria. It may be a criterion of maximum accuracy or speed, minimum weight, power, or inertia, highest rigidity, etc. Thus a whole spectrum of electromechanical and electronic properties is collected, from which a solution is chosen.

In this paper a new design technique is proposed, based on the automatic simultaneous calculation of gear-motor-converter sets and their analysis for selection of the optimum one by using different criteria. 


\section{THE DESIGN ALGORITHM}

The design algorithm depends on whether acceleration is limited (slow accurate drive) or unlimited (high performance fast drive) and whether complete converters will be used or the original ones are to be designed. The first technique is more conventional due to its simplicity. The second technique leads to higher efficiency, but sometimes provides a more expensive application. The flowchart of the design algorithm is depicted in Fig. 1.

First, the travel diagram of the mechanism is developed. The initial data for the travel diagram are the mechanism mode of operation, its speed and timing intervals of motion and standstill for possible modes of operation. The long-term mode of operation is typical for trucks, roll-tables, conveyers etc. The intermitted duty is the mode of operation of supports, rotary tables, hoists, cranes etc.

Then, by mechanical calculation, the load torque, power, moment of inertia and angular speed are found. If the load conditions restrict acceleration, the dynamic computation is made at once. As a result, a torque diagram of the load shaft or a power diagram of the load is drawn.

The results obtained during the driving mechanism calculation will be a basis for the requirements of the gear, motor and converter selection. According to the direction of the power flow, a distinction is made between the coaxial or the parallel shaft gear units and the right-angle gear units. With the first, like the spur or helical and planetary gears, power flows linearly, whereas with the last, like the worm and ball screw gears, power is turned through the right angle. The desired torque of the selected gears should exceed any of the calculated load torques. With the data sheets of gears and motors that correspond to the required drive type available, a group of gear types (with different output speeds, if possible) is to be selected using the calculation results. The mechanism forces are converted into equivalent values on the motor shaft through the gear. For each gear type, the motor is selected based on the converted forces and speeds. Then, a power electronic converter is matched to the motor-gear set, which meets all the electrical requirements of the motor. Since the designer has formed a criterion of maximum accuracy or speed, minimum weight, power, or inertia, highest rigidity, etc., the proposed system collects the whole spectrum of the electromechanical and electronic properties, from which the best motor-gear-converter ratio is chosen.

After that it is required to check the dynamic overloading of the optimum drive set. For systems with the cycling mode of operation, an equivalent load heating evaluation is necessary. For asynchronous drives, the periodic operation of which includes a pause when the motor is at a standstill, the cyclic duration factor (permissible number of stops and starts per hour) is to be calculated.

It is followed by the simulation of the open-loop system using an original simulation software. Unlike the known simulation tools (for example $\left[{ }^{8}\right]$ ) the proposed package is tightly integrated with the database equipment. On the last stage, a control system that includes some regulators and sensors is designed. 


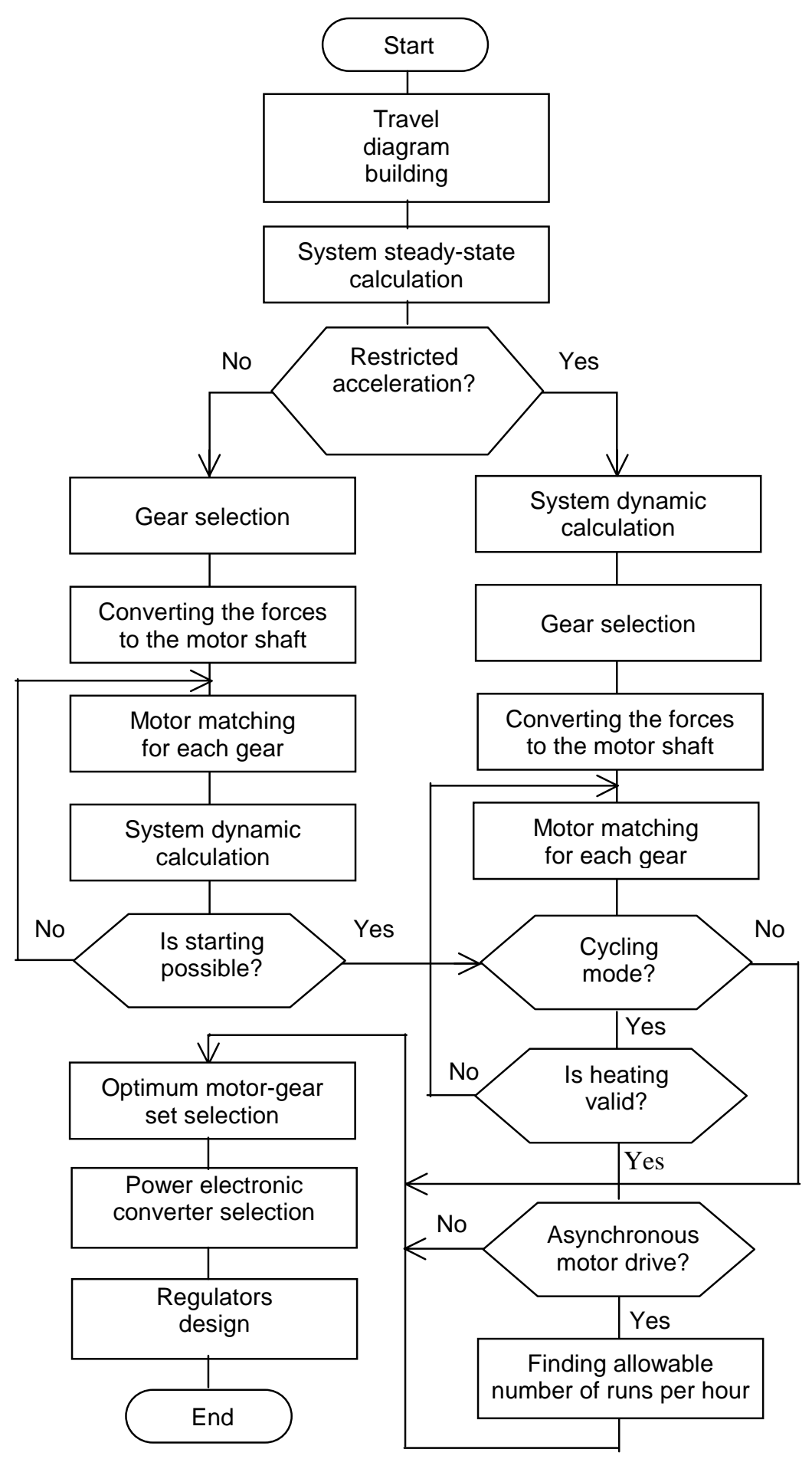

Fig. 1. The design algorithm. 
Their transfer functions, gains, factors, and time constants are calculated to meet the standard settings. Then, the closed-loop system is tested on the model and, if necessary, optimized.

\section{QUERY LANGUAGE TO PROCESS DATABASES OF THE DRIVE COMPONENTS}

Different manufacturers have developed hundreds of databases that facilitate most of the design stages described above. These datasheets provide the following input to the electric drive design:

- parameters of motors with various action and construction principles, powers and speeds; each motor is specified by its rated torque, moment of inertia, mass, efficiency and a list of electrical values;

- specifications of transmissions, distinguished by design and construction, power and ratio; each gear-box has its rated and maximum torque, primary and secondary speeds, moment of inertia, mass and efficiency;

- the nameplate data of industrial electrical power converters with the ac and dc principles and different powers; each record includes rated and maximum voltages, currents, frequencies and efficiency.

These data sheets are prepared by various manufacturers using different languages and operation systems. They have multiple structures, data types, data fields, keys, names, and inter-sheet connections. Not all the data required are published in the sheets; some know-how of manufacturers is concealed from the users. Often the information has an advertizing character that a designer does not benefit from. Some data can be accessed in the Internet or in printed materials and journals.

To obtain access to the required information, the described data sources were connected to a new united database. Specific software has been developed for the selected connection $\left[{ }^{9,10}\right]$. The uniform structure, data types, keys and tables have also been prepared. Then, using a structured query language (SQL), a number of templates were developed, in which calculated data should be substituted to find the sets of the drive components.

A query language gives a set of rules and tools that help the user to search the required information in the databases. As a query answer, a database management system shows the result in the form of a screen (virtual) table that displays a record set of a certain structure, which may be used to build a real summary table, report, or a new query. Today, SQL is an international standard of query languages used in all databases around the world. Data search is not the only operation of SQL. The language provides table creation, control, connection and edition as well.

SQL grammar is based on SQL statements, such as CREATE, INSERT, SELECT etc. Each SQL query points out the operation required to obtain the input data for the output dataset generation, returning the result as a new table. 
To specify the actions upon the processed data, additional SQL arguments indicate the table and field names, relations and conditions. Besides, a number of analyser functions and operators may be included into the query, for instance, substitution signs $(?, *, \#)$, limiting signs (semicolon, point, apostrophe), range restrictors (LIKE, BETWEEN), etc. Logical operators AND, OR, NOT link sections of SQL statements.

Each statement includes variables, which are the names and values of particular tables, fields, and keys. For example,

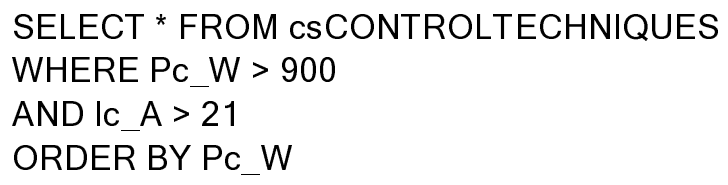

This statement searches all the records in the table csCONTROLTECHNIQUES, which satisfy the requirement that the candidate converter power must exceed 900 and current must exceed 21, while the obtained records have to be ordered alphabetically on the screen.

The next statement searches information in three tables simultaneously with on-line calculation of dependent parameters. Here, gears, motors, and converters are selected together with matching powers (P_W), torques (M_Nm), rotational and linear speeds (n_rpm, vg_cms), moments of inertia (J_kgcm2), and currents (Ic_A):

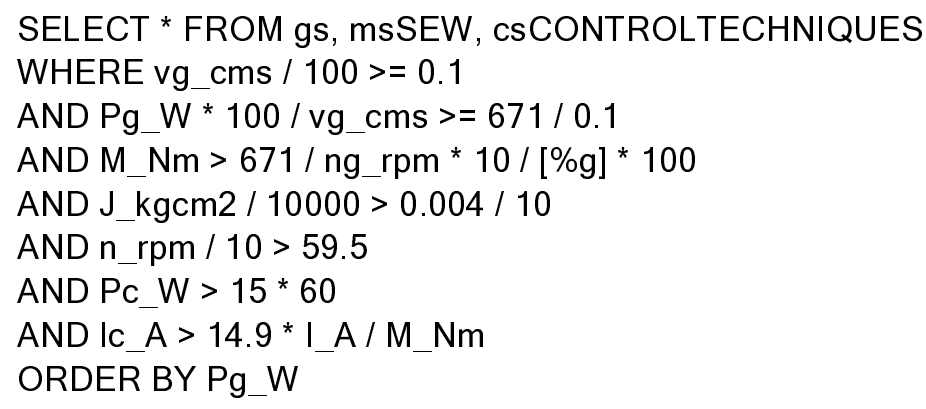

\section{DATABASE MANAGEMENT SYSTEM}

Further, a soft tool was developed to build the necessary SQL statement templates and to insert the arguments into these templates. The proposed software includes a comfortable Windows interface with dialog boxes and SQL edition environment. The required databases link to the package automatically or manually using the Options window of the program shown in Fig. 2.

The first tab of the database window in Fig. 3 shows the list of tables used to find data as well as the detailed data sheets with the drive component records. Figure 4 depicts the SQL editor page with all the needed instruments to write, copy, cut, paste, delete, insert and check the language components and SQL 
statements. Further, Fig. 5 presents the combined result of the query running, where the matched sets of motors, gears, and converters are ranged in the preferred order.

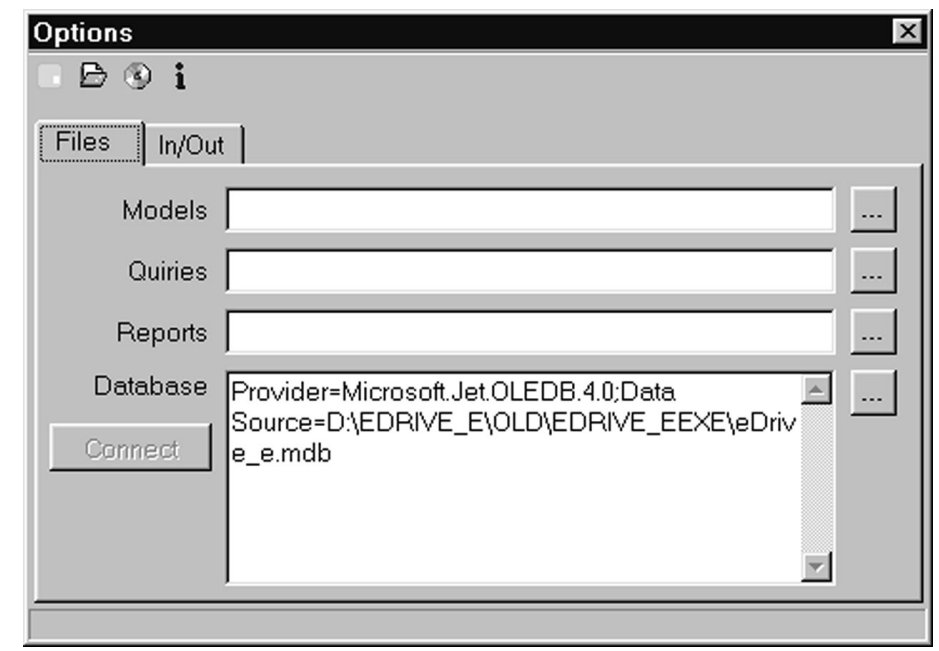

Fig. 2. Database connection window of the software user interface.

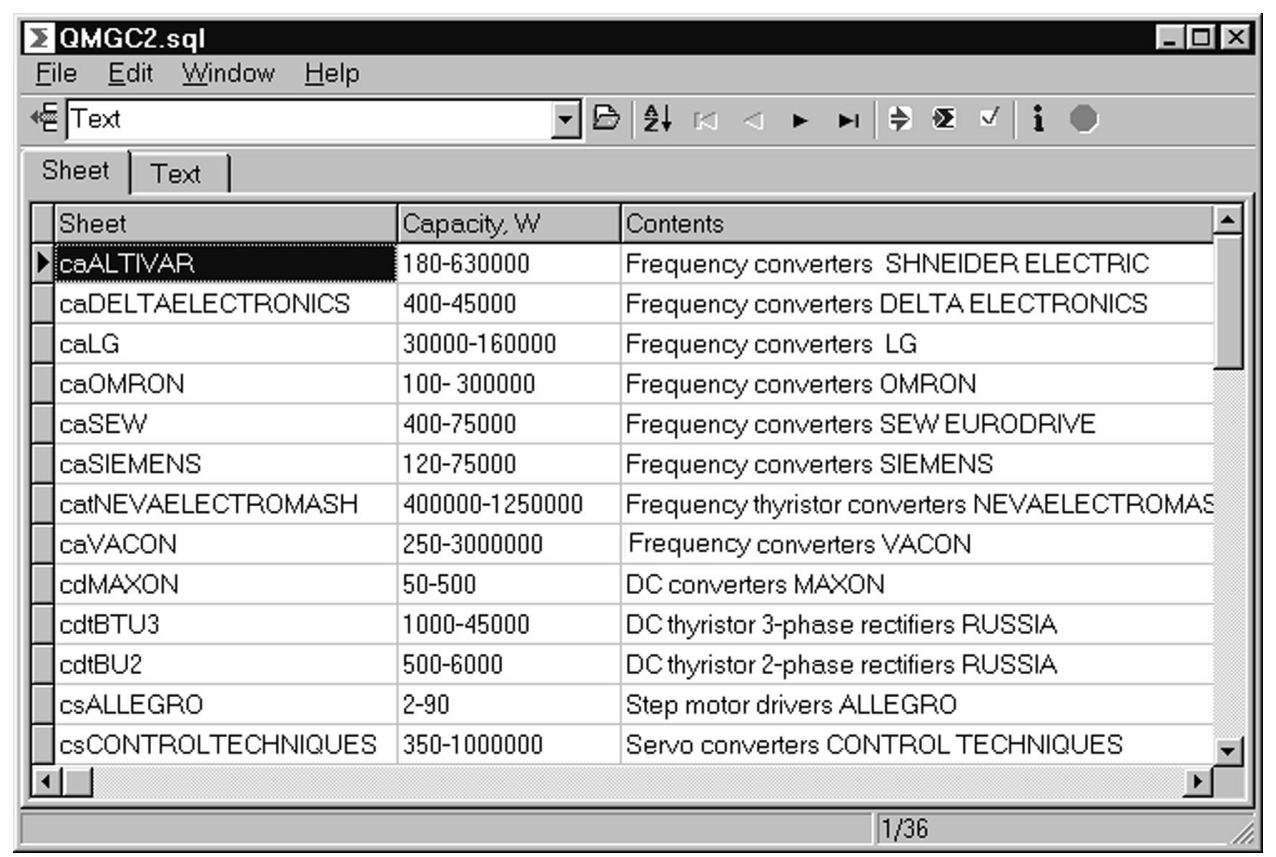

Fig. 3. The tab with the table of contents on the database screen. 


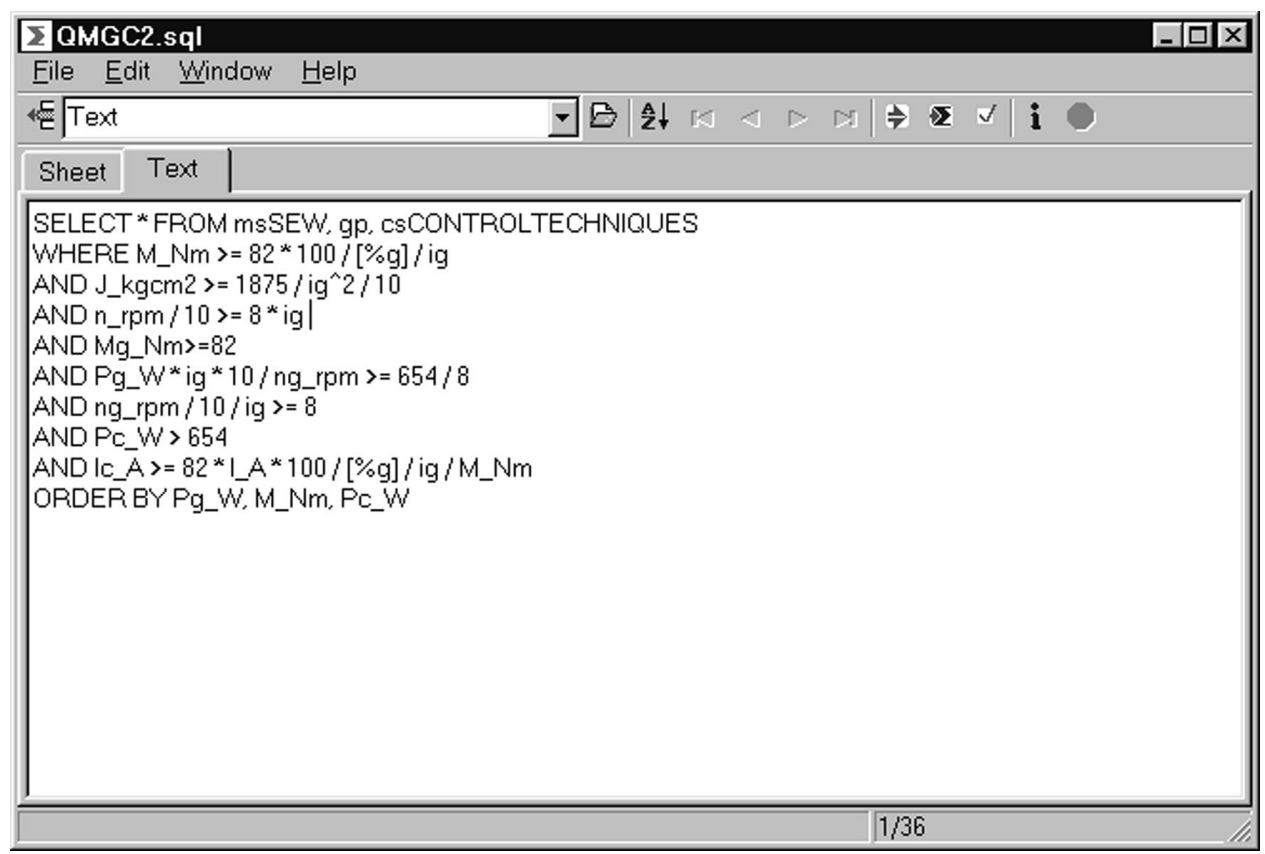

Fig. 4. SQL editor tab of the database screen.

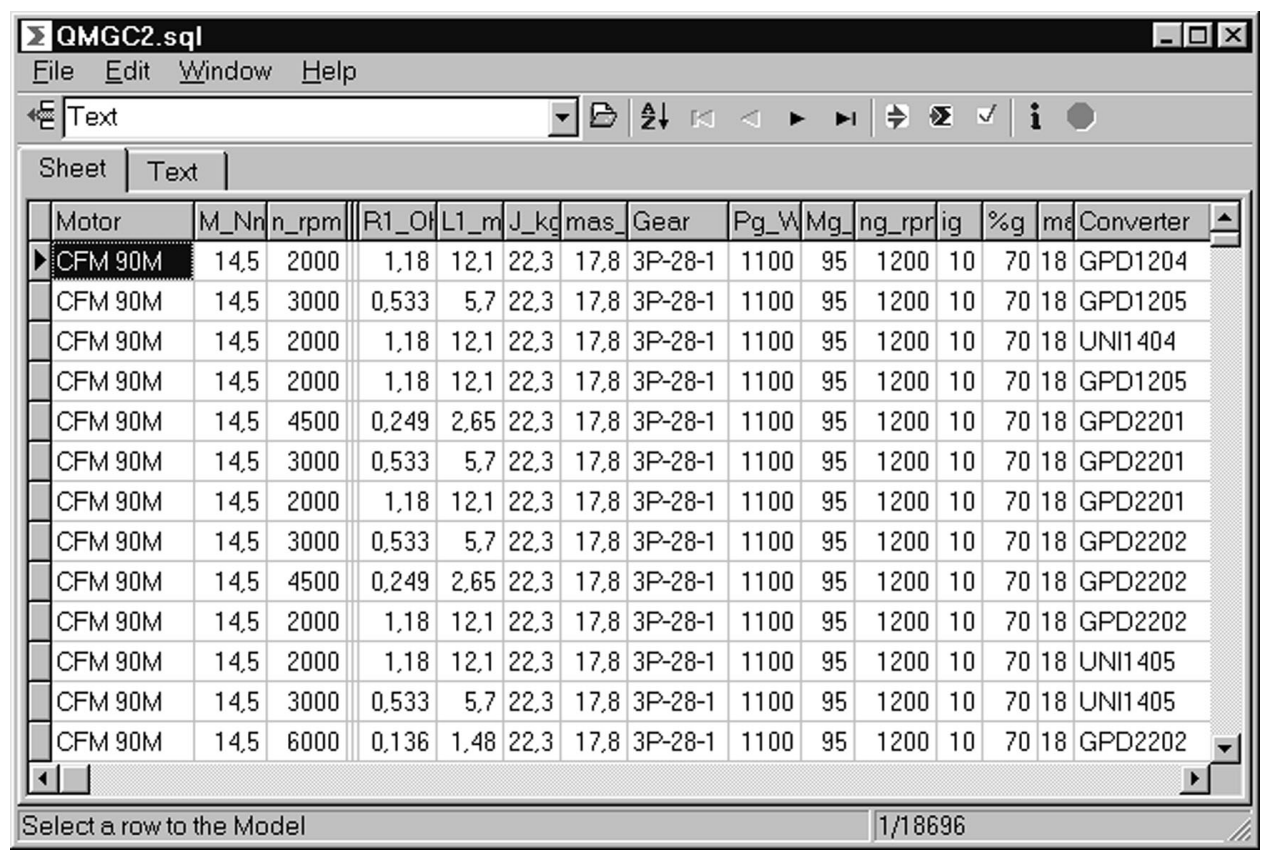

Fig. 5. Result of the SQL query running. 


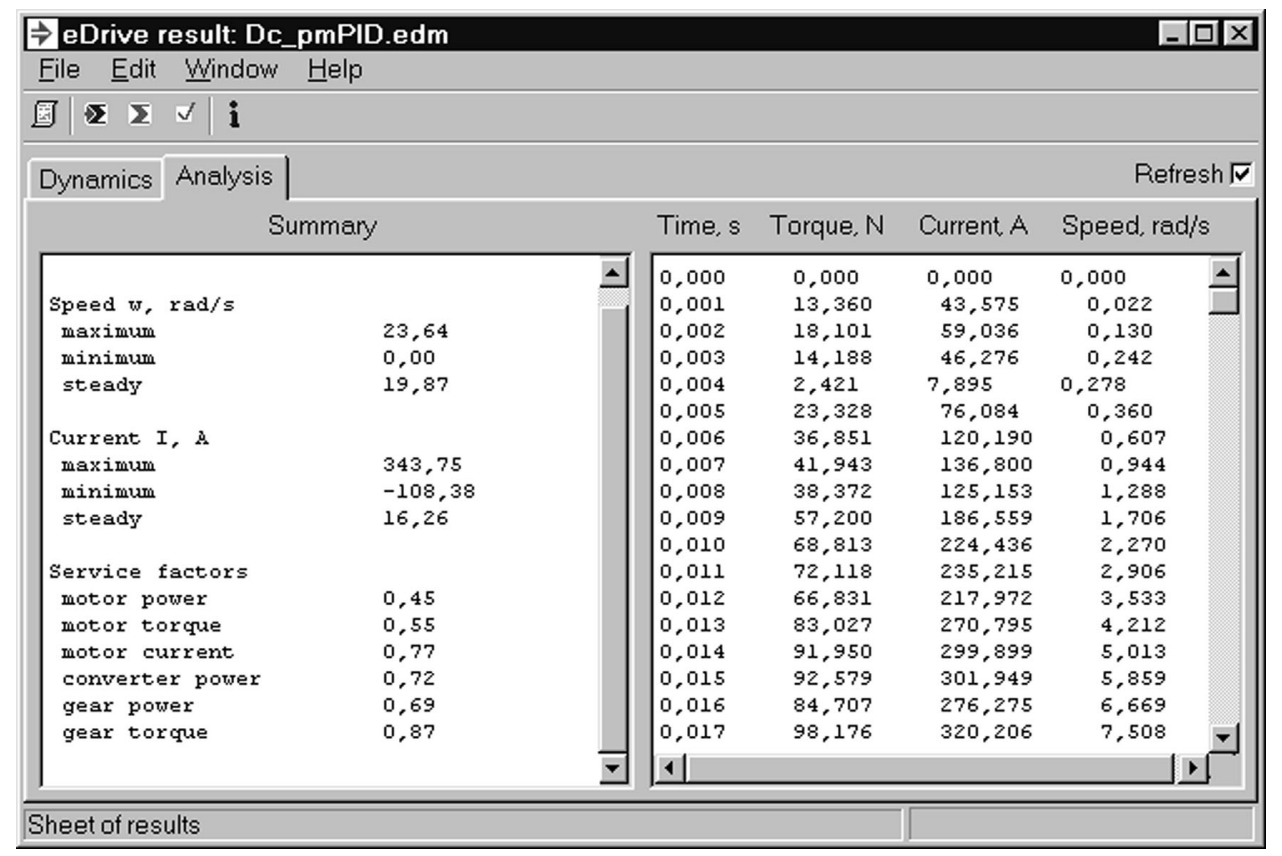

Fig. 6. Simulation analysis window with the steady state conditions, service factors and detailed transients information.

All the information, selected using SQL, may be inserted into the drive model to check its correctness and efficiency in the common gear-motor-converter dataset. To execute simulation, the Result window is opened through the menu. The three tabs display the simulation result: Dynamics, Statics, and Analysis. Any change of the model provides the window Result updating when it is activated. Here, the tab Dynamics represents the speed transients of the mechanism and the torque or the current transients of the motor. The values of variables may be measured at the points where the curves are crossed by the vertical line of the cursor. The program indicates them in the status bar. The tab Statics displays idealized speed-current or speed-torque relations in the openloop system.

The simulation analysis screen shown in Fig. 6 contains the following:

- table of instantaneous values of torque, current, and speed;

- summary of maximum, minimum and steady-state values of variables;

- data calculated in the process of simulation;

- summary of service factors of the drive equipment that are calculated as the steady-to-rated (in the case of the step signal) or rms-to-rated (in other cases) values ratio

- if the motor rated power has been specified in the database, the motor power service factor is obtained as the product of motor torque and motor speed divided by motor power, and the motor torque service factor is obtained as 
the ratio of steady (rms) torque value and the quotient obtained when rated power is divided by the motor speed;

- if the motor rated torque has been specified in the database, the motor torque service factor is obtained as the ratio of the steady (rms) torque and the rated torque values;

- if the motor rated current has been specified in the database, the motor current service factor is obtained as the ratio of the steady (rms) current and the rated current values;

- if the converter rated power has been specified in the database, the converter power service factor is obtained as the ratio of the motor torque-speed product and the rated converter power;

- if the gear rated power has been specified in the database, the gear power service factor is obtained as the ratio of the load torque-speed product and the gear rated power;

- if the gear transmission ratio and rated torque have been specified in the database, the gear torque service factor is obtained as the product of the steady (rms) torque and the transmission ratio divided by the gear rated torque.

The selected components may be used in the project since the simulation results satisfy the designed requirements. If the results are unsatisfactory, new SQL queries have to be created to continue the search of optimum drive components.

\section{CONCLUSIONS}

An approach to the optimum component search for a designed motor drive has been proposed. This approach is based on the implementation of the SQL in the design stages that involve work with databases. Examples of effective algorithms are given to choose an optimum ratio of electrical and mechanical components. A soft tool is described to generate and edit SQL sentences, to extract information from databases, as well as to test different component sets for particular applications. The results obtained help to increase equipment service factors and to avoid unwarranted complexity or excessive motor drive cost.

\section{REFERENCES}

1. Vodovozov, V. Theory and Systems of Electric Drives. ETU Publishing, St. Petersburg, 2004 (in Russian).

2. Cetinkunt, S. Optimal design issues in high-speed high-precision motion servo systems. Mechatronics, 1991, 1, 187-201.

3. Roos, F., Johansson, H. and Wikander, J. Optimum selection of motor and gearhead in mechatronic applications. Mechatronics, 2006, 16, 63-72.

4. Siemens Standard Drives. Application Handbook. Congleton, 1997. 
5. Drive Engineering - Practical Implementation. Vol. 1. Drive Arrangements with SEW Geared Motors. Calculation Methods and Examples. SEW Eurodrive, 1998.

6. Vodovozov, V. and Loparev, A. Simulation tools for design and testing of electric drives. In Proc. 10th International Power Electronics and Motion Control Conference EPE-PEMC2004. Riga, 2004, paper DS 7.16.

7. Vodovozov, V. and Laugis, J. Object-oriented electric drive development technology. In Proc. IEEE International Electric Machines and Drives Conference IEMDC'07. Antalya, 2007, paper AF000434.

8. Ergodian, N., Hemao, H. and Grisel, R. A Proposed technique for simulating the complete electric drive systems with a complex kinematics chain. In Proc. IEEE International Electric Machines and Drives Conference IEMDC'07. Antalya, 2007, paper AF014095.

9. Vodovozov, V., Vodovozova, E. and Tsvetikov, E. Object-oriented models of electromechanical systems. In Proc. 8th European Simulation Symposium "Simulation in Industry”. Genoa, 1996.

10. Vodovozov, V., Pettai, E. and Auväärt, A. Design and modelling of electric drive in database environment. In Proc. 2008 IEEE International Symposium on Industrial Electronics. Cambridge, 2008.

\section{Elektriajamite projekteerimine struktureeritud päringukeele abil}

\section{Valery Vodovozov ja Juhan Laugis}

On käsitletud elektriajamite projekteerimist, mis põhineb struktureeritud päringukeele kasutamisel. See võimaldab tõhustada tööd elektriajami komponentide andmebaasidega ja aitab valida elektriliste ning mehaaniliste komponentide optimaalset suhet. Täiendavalt pakub keel võimalusi päringulausete moodustamiseks ja redigeerimiseks, päringute tegemiseks andmebaasidest ning eri rakenduste jaoks kasutatavate komponentide kontrollimiseks. 